\title{
Markers of collagen and basement membrane metabolism in sera of patients with progressive systemic sclerosis
}

Natalia G Guseva, Natalia V Anikina, Raili Myllylä, Leila Risteli, Juha Risteli, Julia V Chochlova, Kari I Kivirikko, Valentina A Nassonova

\begin{abstract}
The concentrations of the amino terminal propeptide of type III procollagen, the 7S domain of type IV collagen, and the fragment P1 of laminin (PIINP, 7S, and P1 respectively) and the activity of galactosylhydroxylysyl glucosyltransferase (GGT) in serum were evaluated as indicators of disease activity in a cross sectional study of 84 patients with progressive systemic sclerosis.

The mean values of PIINP, P1, and GGT were raised in progressive systemic sclerosis, $19-32 \%$ of patients having abnormal values of the various tests. PIINP, measured with two different assays, and P1 were associated with active, acute, or subacute disease. GGT also correlated positively with some acute phase proteins in the whole group, without a clear association with the course of the disease. Arthritis was associated with increased PIIINP concentrations as well as with an increased activity of GGT. Kidney disease led to raised concentrations of the degradation products of PIIINP. Raynaud's phenomenon in the hands was related to increased PIIINP concentrations.
\end{abstract}

Progressive systemic sclerosis is characterised by an excessive accumulation of collagen in various tissues, including skin, subcutaneous tissues, lungs, and other internal organs. ${ }^{1-4}$ Fibrosis of the affected organs seems to be at least partly due to excessive collagen production by fibroblastic cells, a phenomenon that can be shown in cultured fibroblasts both as increased amounts of mRNA for collagen types I and III and as increased accumulation of polypeptides containing hydroxyproline. ${ }^{56}$ Also the activities of prolyl and lysyl hydroxylases, two enzymes participating in collagen biosynthesis, are higher than in control cells. ${ }^{7}$ Raised type III/type I collagen ratios have been found in the skin and kidneys of patients with progressive systemic sclerosis. ${ }^{8} 9$

During recent years several methods have been introduced that allow assessment of the activity of connective tissue metabolism in patients by analysing blood samples. These are based on the measurement of some of the enzymes of collagen biosynthesis, fragments of procollagen or collagen molecules, or known parts of non-collagenous basement membrane proteins. ${ }^{10-12}$ The method most studied has been the assay for the amino terminal propeptide of type III procollagen. This antigen is partially set free during the synthesis of collagen, before the collagen molecules assemble to form fibrils, and partially derived from the remodelling and turnover of such type III collagen molecules that have retained this propeptide while already on the surface of type III collagen fibres. ${ }^{13}$ In normal serum most of the propeptide antigenicity is due to quite small degradation products, which, however, react with a lower affinity with most antisera.

It has been suggested that the serum concentration of the antigens related to the amino terminal propeptide of type III procollagen is increased in progressive systemic sclerosis and that this increase is detected best by an assay that preferentially measures the small degradation products. ${ }^{14}$ The aim of the present study was to find out how the serum concentration of the amino terminal propeptide is related to the clinical features and to other laboratory indices of progressive systemic sclerosis. In addition, we wanted to see whether this disease, which is known to affect small arteries and capillaries, influences the serum concentrations of two basement membrane protein antigens, the $7 \mathrm{~S}$ domain of type IV collagen and the fragment P1 of laminin. Finally, the activity of galactosylhydroxylysyl glucosyltranferase (GGT), an enzyme participating in the biosynthesis of collagen and known to preserve its activity in serum, was studied in progressive systemic sclerosis.

\section{Patients and methods}

PATIENTS

Table 1 gives the clinical characteristics of the patients studied. All patients had been admitted to the clinical department of the Institute of Rheumatology in Moscow during the years 1981 to 1986.

Each patient had a complete history taken and physical examination made. All patients met the criteria for the diagnosis of progressive systemic sclerosis. ${ }^{15}$ Four (5\%) of the patients

Table 1 Clinical characteristics of the patients studied. Results are shown as number positive/number studied

\begin{tabular}{lc}
\hline Mean age (SD) (years) & $36(10)$ \\
Acrosclerosis & $41 / 84$ \\
Diffuse skin disease & $40 / 84$ \\
Generalised Raynaud's phenomenon & $41 / 84$ \\
Arthritis & $9 / 84$ \\
Basal pneumosclerosis & $22 / 84$ \\
Diffuse lung disease & $12 / 84$ \\
Cardiosclerosis & $59 / 84$ \\
Oesophagus disease & $48 / 84$ \\
Kidney disease & $34 / 84$ \\
Erythrocyte sedimentation rate $\geqslant 20 \mathrm{~mm} / \mathrm{h}$ & $22 / 84$ \\
$\alpha_{2}$ Globulins $\geqslant 12 \%$ & $30 / 74$ \\
Positive for C reactive protein & $45 / 77$ \\
Positive for antinuclear antibodies & $35 / 65$ \\
Circulating immune complexes $>130 \mathrm{U} / \mathrm{l}$ & $37 / 65$ \\
\hline
\end{tabular}


had the acute form of the disease (rapid development of cutaneous as well as visceral fibrosing disease, diffuse and generalised skin induration), 55 (65\%) had a subacute form manifested by oedema and limited fibrosing lesions of the skin, arthritis, and sometimes myositis (including three patients with overlap syndrome-that is, rheumatoid-like arthritis and signs of polymyositis or dermatomyositis), and $25(30 \%)$ had chronic progressive systemic sclerosis (CREST (calcinosis, Raynaud's phenomenon, oesophageal dysmotility, sclero: dactyly, telangiectasia) variant) with many years of Raynaud's phenomenon followed by a slow development of cutaneous and visceral fibrosing disease.

Most patients had skin disease: sclerodactyly (41 patients) and proximal scleroderma (40 patients). Only three patients in the early stage of progressive systemic sclerosis had no skin disease, but they had Raynaud's phenomenon and visceral involvement typical of progressive systemic sclerosis. Sixteen (19\%) of the patients had Siögren's syndrome; they all had an immunologically active disease, mostly high concentrations of the rheumatoid factor.

During the study or before it all the patients had been subjected to treatment that could affect collagen metabolism. Forty five patients received moderate doses of prednisolone (10-20 $\mathrm{mg} /$ day) and 18 patients D-penicillamine (300 $600 \mathrm{mg} /$ day).

Oesophageal dysfunction was studied by barium oesophagography. Renal disease was defined as acute or chronic nephropathy (creatinine clearance less than $70 \mathrm{ml} / \mathrm{min}$ or proteinuria greater than $500 \mathrm{mg} / 24 \mathrm{~h}$ ). Proteinuria was not specifically related to treatment with D-penicillamine (see 'Results').

\section{BLOOD SAMPLES}

Venous blood samples were taken between 800 and 900 am after an overnight fast and at least one hour's rest. For analysis of the extracellular matrix related metabolites the blood was allowed to clot for one and a half hours at room temperature before separating the serum by centrifugation. The serum samples were stored for up to six months at $-20^{\circ} \mathrm{C}$ without thawing. As reported previously ${ }^{16} 17$ these conditions preserve the activity of serum GGT. The results of the four extracellular matrix protein radioimmunoassays are not affected by even longer periods of storage.

\section{ASSAYS}

The activity of serum GGT was analysed by measuring the amount of radioactive glucosylgalactosylhydroxylysine formed from UDP $-\left[{ }^{14} \mathrm{C}\right]$ glucose in a gelatinised calf skin collagen substrate. ${ }^{16}$ One unit of GGT activity was defined as described earlier. ${ }^{18}$

The radioimmunoassays for two basement membrane antigens-the 7S domain of human type IV collagen and the fragment $P 1$ of human laminin-have been described previously. ${ }^{19}$ The amino terminal propeptide of type III procollagen was measured by two different commercial radioimmunoassays: one, termed here PIIINP, detects both larger antigen forms, including the intact aminopropeptide, and small degradation products of the antigen, the latter with a lower affinity, however, ${ }^{20} 21$ whereas the other, termed here PIIINP-Fab, preferentially measures the degradation products. ${ }^{22}$ Both of these PIIINP assays were carried out with kits from Behringwerke, Marburg, FRG. The results in the laminin $\mathrm{Pl}$ assay and in the PIIINP assay were calculated with a $50 \%$ intercept method ${ }^{10}$ because of absence of parallelism between inhibition curves of serum samples and of reference inhibitors.

\section{REFERENCE INTERVALS}

The mean (SD) of serum GGT in 77 healthy adults was $0.43(0.07) \mathrm{U} / \mathrm{l}$, the upper normal limit (mean $+2 \mathrm{SD}$ ) thus being $0.57 \mathrm{U} / \mathrm{l}$. For the PIIINP antibody assay, samples of 35 healthy volunteers gave a value of $8.4(1 \cdot 6) \mu \mathrm{g} / \mathrm{l}$; $12 \mu \mathrm{g} / \mathrm{l}$ was used as upper limit of the reference interval. The corresponding values for the PIIINP-Fab assay were $39(12) \mu \mathrm{g} / 1$ and $63 \mu \mathrm{g} / 1$ respectively, and for laminin Pl $26(5.5) \mu \mathrm{g} / 1$ and $37 \mu \mathrm{g} / 1$ respectively. For the $7 \mathrm{~S}$ domain of type IV collagen, concentrations exceeding 10 $\mu \mathrm{g} / \mathrm{l}$ were considered pathological. ${ }^{19}$ It has been shown earlier that in adults there is no variation with age or sex in these values. ${ }^{16192022}$

\section{STATISTICAL METHODS}

A one way analysis of variance was used to analyse the statistical significance of the differences between more than two groups. The significance was then tested using a modified $t$ test and the critical $t$ value calculated by the Bonferroni method. ${ }^{23}$ The significance of the difference between two independent groups was analysed with Student's $t$ test. The correlations between different variables were analysed using the Spearman rank correlation coefficient. ${ }^{24}$ The possible association of impaired kidney function with $D$-penicillamine treatment was tested with the $\chi^{2}$ test. $^{24}$

\section{Results}

\section{MARKERS OF COLLAGEN AND BASEMENT} MEMBRANE METABOLISM IN PROGRESSIVE SYSTEMIC SCLEROSIS

Figure 1 shows the individual values for the five variables related to the metabolism of collagens and basement membranes. The upper limits of the reference ranges for PIIINP, PIIINP-Fab, laminin P1, and GGT were exceeded by $26 / 81$ (32\%), 20/79 (25\%), 15/78 (19\%), and 18/83 $(22 \%)$ of the patients respectively, whereas only one patient had a raised serum $7 \mathrm{~S}$ collagen concentration.

The mean values of four of the measured variables were significantly higher in the patients with progressive systemic sclerosis than in the reference group. They were PIIINP (mean (SD) $12(6.5) \mu \mathrm{g} / \mathrm{l}, \mathrm{p}<0.01$ ), PIIINP-Fab (56 (22) $\mu \mathrm{g} / \mathrm{l}, \mathrm{p}<0.001$ ), laminin P1 (31 (8) $\mu \mathrm{g} / \mathrm{l}$, $p<0.01)$, and serum GGT $(0.50(0.14) \mathrm{U} / \mathrm{l}$, $p<0.001)$. The serum concentration of the $7 S$ 


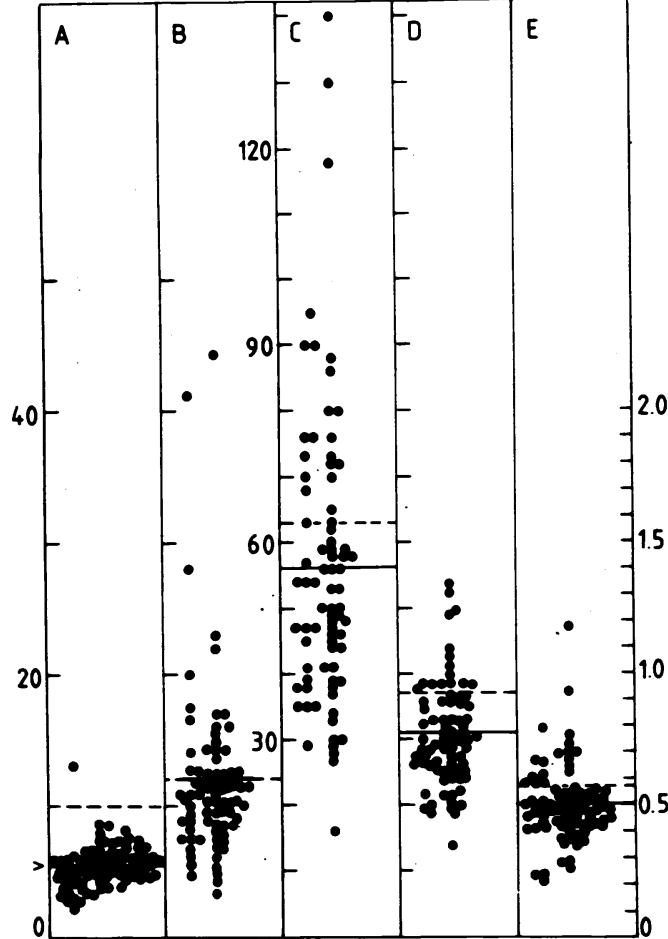

Figure 1 Concentrations of $(A)$ the $7 S$ domain of type IV collagen $(\mu g / l) ;(B) P I I I N P(\mu g / l) ;(C) P I I I N P-F a b$ $(\mu g / l)$ and $(D)$ the fragment $P I$ of laminin $(\mu g / l)$; and $(E)$ the activity of galactosylhydroxylysyl glucosyltransferase $(U / l)$ in serum samples of patients with progressive systemic sclerosis. The dashed lines indicate the upper limits of the reference ranges (mean $+2 S D$ ). The continuous horizontal line shows the mean value for the patients with progressive systemic sclerosis; in B this lies exactly on the corresponding dashed line. The mean for the patient group in $A$ is additionally marked with an $>$. Note the different scales ( $A$ and $B$ having a common scale, $C$ and $D$ likewise, and $E$ having the scale indicated furthest to the right).

collagen antigen was $5.5(1.6) \mu \mathrm{g} / \mathrm{l}$; in this respect the patient group did not differ from the controls.

RELATION TO OTHER LABORATORY INDICES OF DISEASE ACTIVITY

Table 2 lists the laboratory indices that correlated significantly with any of the extracellular matrix metabolites.

The results of both assays for the amino terminal propeptide of type III procollagen, PIIINP and PHINP-Fab, correlated with the concentration of circulating immune complexes and were significantly higher in the patients with antinuclear antibodies or an increased $\mathrm{C}$ reactive protein concentration than in those

Table 2. Correlation between the serum markers of collagen and basement membrane metabolism and other laboratory indices*

\begin{tabular}{lrrrrrr}
\hline Serum markers & ESRt & \multicolumn{1}{c}{$\alpha_{2}$ Globulins } & Orosomucoid & CRPt & ANAt & CICt \\
\hline 7S domain & -0.006 & -0.322 & -0.402 & & & \\
& 0.957 & 0.006 & 0.001 & 0.617 & 0.183 & 0.174 \\
PIIINP & 0.125 & 0.145 & 0.199 & & & 0.396 \\
& 0.266 & 0.225 & 0.071 & 0.028 & 0.011 & 0.002 \\
PIIINP-Fab & 0.229 & 0.151 & 0.212 & & & 0.405 \\
& 0.040 & 0.206 & 0.058 & 0.029 & 0.034 & 0.002 \\
Laminin P1 & 0.224 & 0.196 & 0.209 & & & 0.294 \\
& 0.046 & 0.106 & 0.063 & 0.659 & 0.063 & 0.025 \\
Serum GGT & 0.098 & 0.303 & 0.264 & & & 0.040 \\
& 0.617 & 0.009 & 0.015 & 0.781 & 0.959 & 0.755
\end{tabular}

*The table shows the Spearman rank correlation coefficients(above) and the p values(below). Creactive protein and antinuclear antibodies were measured qualitatively: for thesemeasurements the p value of Student's $t$ test for two independent groups is given.

$+\mathrm{ESR}=$ erythrocyte sedimentation rate; $\mathrm{CRP}=\mathrm{C}$ reactive protein; $\mathrm{ANA}=$ antinuclearantibodies CIC=circulating immune complexes. without these findings. In addition, the results of the PIIINP-Fab assay correlated positively with the erythrocyte sedimentation rate. The changes in the concentration of the laminin P1 antigen somewhat resembled those detected by the PIIINP-Fab assay, erythrocyte sedimentation rate and circulating immune complexes giving significant correlations with laminin Pl. In contrast, the concentration of the $7 \mathrm{~S}$ collagen domain of type IV collagen did not correlate positively with any of the laboratory indices recorded, but showed a negative correlation with the serum concentrations of $\alpha_{2}$ globulin and orosomucoid. The activity of the glucosyltransferase, on the other hand, correlated positively with these two acute phase reactants.

\section{RELATION TO CLINICAL FEATURES}

Of the clinical characteristics of the patients studied, disease of the lungs, the oesophagus, or the heart did not explain the differences in serum concentrations of the collagen and basement membrane markers, nor was there any difference between the patients with the CREST syndrome and those with diffuse scleroderma. The presence or absence of Sjögren's syndrome did not explain the serum indices either. Table 3 shows the clinical characteristics which were found to influence the serum markers studied.

Impairment of renal function was associated with increased serum concentrations of PIIINPFab. Two of these patients have died and were found to have typical sclerodermatous kidneys: their PIIINP-Fab values were 95 and $72 \mu \mathrm{g} / \mathrm{l}$, whereas the PIIINP values measured with the antibody assay were at the upper limit of the reference range. Table 4 gives a more detailed analysis of the relation between kidney function and PIIINP-Fab. D-Penicillamine treatment clearly does not explain the proteinuria or the decreased creatinine clearance, which were found in about one fifth of the patients. The mean serum concentration of fragmented PIIINP, as measured by the PIIINP-Fab assay, was significantly higher in patients with proteinuria than in those without it. A similar, although not statistically significant, association was noted between PIIINP-Fab results and impaired creatinine clearance (not shown). Of the other extracellular matrix markers, laminin P1 tended to increase with impaired kidney function, though the difference did not reach significance.

PIIINP was related to the presence of Raynaud's phenomenon in hands. Again, the laminin Pl values tended to differ between the groups, but the difference was not significant.

The presence of arthritis was related to increased serum concentrations of PIIINP and PIIINP-Fab and an increased activity of the glucosyltransferase.

The patients were divided into three groups according to the course of their disease (acute, subacute, chronic). There were significant differences between these groups for the laminin P1 and PIIINP-Fab-patients with an acute disease having the highest and those with a chronic course of disease having the lowest mean values (fig 2 ). 
CORRELATIONS BETWEEN THE DIFFERENT INDICATORS OF COLLAGEN AND BASEMENT MEMBRANE METABOLISM

Table 5 shows the correlations found between the different markers of collagen and basement membrane metabolism. There was a highly

Table 3 Association of serum markers of collagen and basement membrane metabolism with organ involvement of progressive systemic sclerosis. Results are shown as the p values for the differences, calculated with Student's $t$ test for two independent groups

\begin{tabular}{llll}
\hline Serum markers & Arthritis & $\begin{array}{l}\text { Kidney } \\
\text { disease }\end{array}$ & $\begin{array}{l}\text { Raynaud's phenomenon } \\
\text { in hands }\end{array}$ \\
\hline 7S domain & $0 \cdot 106$ & 0.304 & $0 \cdot 128$ \\
PIIINP & 0.005 & 0.275 & 0.050 \\
PIIINP-Fab & 0.046 & 0.007 & $0 \cdot 135$ \\
Laminin P1 & 0.154 & $0 \cdot 108$ & 0.057 \\
Serum GGT & 0.001 & 0.662 & 0.284 \\
\hline
\end{tabular}

Tuble 4 Renal status of the patients in relation to D-penicillamine treatment and PIIINP-Fab values

\begin{tabular}{|c|c|c|c|}
\hline & \multicolumn{2}{|l|}{ D-Penicillamine* } & \multirow{2}{*}{$\frac{P I I I N P-F a b}{(\mu g / l)(\text { mean }(S D))}$} \\
\hline & $\begin{array}{l}\text { With treatment } \\
(n)\end{array}$ & $\begin{array}{l}\text { Without treatment } \\
(n)\end{array}$ & \\
\hline $\begin{array}{l}\text { Proteinuria } \\
\text { No proteinuria }\end{array}$ & $\begin{array}{r}7 \\
10\end{array}$ & $\begin{array}{l}27 \\
40\end{array}$ & $\begin{array}{l}64(27)^{* *} \\
51(17)\end{array}$ \\
\hline
\end{tabular}

${ }^{*}$ No difference in the prevalence of proteinuria between patients with and without D-penicillamine treatment $\left(\chi^{2}\right.$ test).

** Significantly different from the corresponding concentration of the patients without proteinuria $(\mathrm{p}<0.01$; Student's $t$ test).
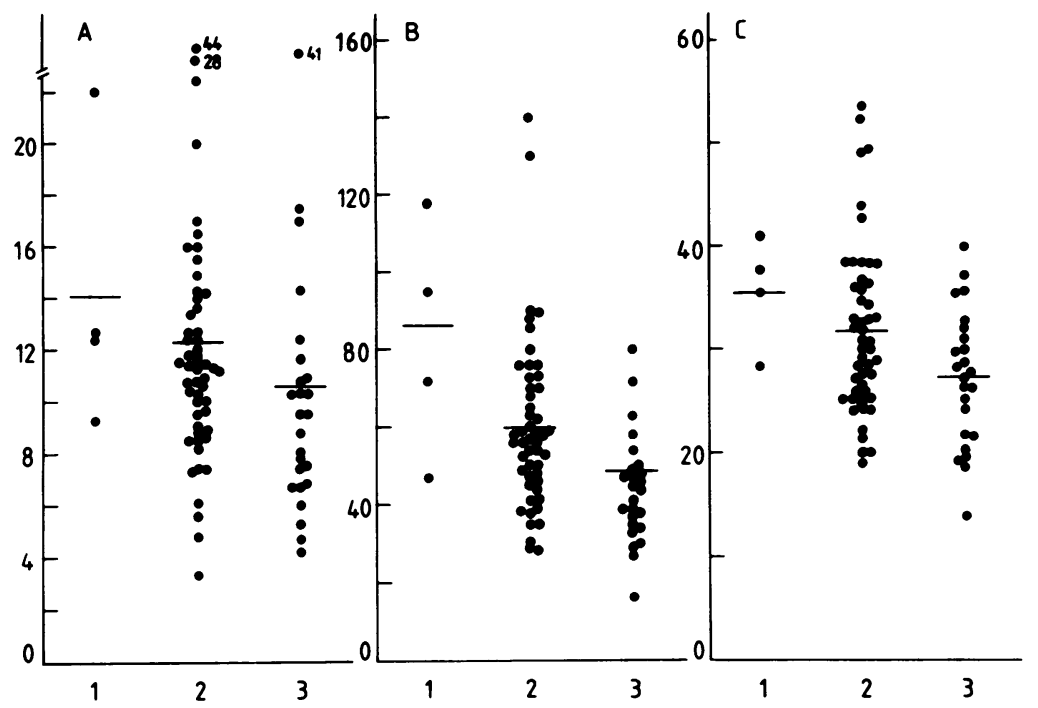

Figure 2 Concentrations $(\mu g / l)$ of (A)PIIINP; (B) PIIINP-Fab; and $(C)$ the fragment $P I$ of laminin in serum samples of patients with progressive systemic sclerosis divided into three groups according to the course of the disease: (1) acute; (2) subacute; and (3) chronic. The horizontal lines indicate the mean values of the groups. In $A$ the groups are not statistically different. In $B$ the difference between groups 1 and 2 is almost significant $(p<0.05)$, that between 2 and 3 significant $(p<0.01)$, and that between 1 and 3 highly significant $(p<0.001)$. In $C$ the difference between groups 1 and 2 is not significant, but the differences between group 3 and either of the other groups are almost significant $(p<0.05)$.

Table 5 Correlations between the different markers of collagen and basement membrane metabolism in patients with progressive systemic sclerosis. Results are shown as the correlation coefficients (Spearman's rank correlation) above with the corresponding $p$ value below

\begin{tabular}{lcllll}
\hline Serum markers & $7 S$ domain & PIIINP & PIIINP-Fab & Laminin PI & Serum GGT \\
\hline 7S domain & 1.000 & & & & \\
PIIINP & 0.210 & 1.000 & & & \\
& 0.057 & & & & \\
PIIINP-Fab & 0.152 & 0.744 & 1.000 & & \\
& 0.184 & 0.001 & & & \\
Laminin P1 & 0.181 & 0.486 & 0.649 & 1.000 & \\
Serum GGT & 0.109 & 0.001 & 0.001 & & \\
& -0.043 & 0.186 & 0.162 & -0.065 & 1.000 \\
& 0.705 & 0.093 & 0.150 & 0.580 & \\
\hline
\end{tabular}

significant correlation between the two assays for PIIINP. Laminin P1 also correlated with both of these, the correlation with the Fab assay being stronger.

\section{Discussion}

The aim of this study was to find out whether the development of fibrosis in progressive systemic sclerosis is accompanied by such changes in collagen and basement membrane related metabolites in serum that they could be assumed to aid in the follow up of the disease process. Five different methods were evaluated in a cross sectional investigation of 84 patients with progressive systemic sclerosis.

A number of assays have been described for assessing changes in connective tissue proteins from serum samples. ${ }^{10-13}$ Most of these are based on the immunological detection of defined parts of (pro)collagens or other matrix molecules. Four such assays were used here: two different methods for the amino terminal propeptide of type III procollagen-one mainly measuring the authentic propeptide and an antigen form larger than this (the PIIINP assay with intact antibodies) and the other mainly detecting small degradation products of the propeptide (the PIIINP-Fab assay with Fab fragments of antibodies), a method for the $7 S$ domain of type IV collagen, and a method for the Pl fragment of laminin. In addition, the activity of GGT, an enzyme participating in the biosynthesis of collagen, was measured.

Raised serum concentrations of the amino terminal propeptide of type III procollagen have earlier been found in patients with systemic sclerosis. ${ }^{14} 25-27$ The results of our study indicate that the increases in both the larger forms of PIIINP, as measured by the antibody PIIINP assay, and in the degradation products of this antigen, as detected by the PIIINP-Fab assay, occur during active phases of the disease, as indicated by the presence of immune complexes and antinuclear antibodies. Active arthritis, in particular, was associated with increased PIIINP concentrations; a similar finding has previously been made in rheumatoid arthritis. ${ }^{28}$ In contrast with a previous study on scleroderma ${ }^{14}$ in our series of patients PIIINP-Fab was not pathological more often than PIIINP.

The larger forms of the PIIINP antigen, with molecular weights of about 42000 daltons and higher, are taken up from the circulation and further metabolised by the endothelial cells of the liver. ${ }^{29}$ Owing to their elongated shape, these antigens tend to behave like molecules of more than 100000 daltons, thus not passing through the glomerular filter. Recent results indicate that the small degradation products of the PIIINP antigen, measured by the PIIINPFab assay, are removed from blood by the kidneys, which normally degrade most of these peptides to non-antigenic metabolites and excrete the rest into the urine. ${ }^{29}$ In pigs the urinary clearance of these antigens is in fact only $2 \%$ of the total renal clearance. ${ }^{29}$

In our study kidney disease was associated with somewhat raised serum concentrations of the degradation products of PIIINP. The association with proteinuria was more distinct 
than that with impaired creatinine clearance. It should be noted that proteinuria evidently does not lead to an increased excretion of the small degradation products of PIINP: in two patients with massive proteinuria for reasons other than progressive systemic sclerosis we found a daily excretion that was only $1 \cdot 5$-fold higher than the mean of healthy controls. A decreased urinary clearance of the degradation products of PIIINP in progressive systemic sclerosis has also recently been shown by another group. ${ }^{26}$ As the kidneys have a multifunctional role in eliminating the degradation products of PIIINP from the circulation $^{29}$ the exact pathophysiological interpretation of these results is not possible without direct comparison of the concentrations in renal veins and renal arteries.

Increased PIIINP concentrations in serum occur in a number of liver diseases, in particular in hepatitis, as well as in myelofibrosis. ${ }^{10} 13$ There were no indications of either liver or bone marrow being affected in any of the patients studied here.

Small blood vessels are typically affected in progressive systemic sclerosis. One of the aims of this study was to find out whether this microcirculatory disorder is reflected in the serum concentration of the basement membrane derived antigens. This was not the case, however, as the concentration of the $7 \mathrm{~S}$ collagen antigen was hardly changed. The serum antigen detected by this assay is very large in size, ${ }^{19}$ probably representing almost intact type IV collagen molecules, and seems to be derived mostly from tissues with sinusoidal blood vessels, like liver or bone marrow, rather than from tissues with intact capillary walls. ${ }^{10} 13$ The concentration of the laminin $\mathrm{Pl}$ antigen in serum was more affected by the disease, its behaviour in progressive systemic sclerosis resembling that of PIIINP and PIIINP-Fab. During the preparation of this study another group reported slightly raised mean concentrations of the laminin $\mathrm{Pl}$ antigen and the $\mathrm{NCl}$ antigen of type IV collagen in progressive systemic sclerosis ${ }^{30}$; none of these correlated with the activity of the disease, however.

Galactosylhydroxylysyl glucosyltransferase activity in serum has not previously been studied in patients with progressive systemic sclerosis. Although this activity clearly correlated with the increased concentrations of the $\alpha_{2}$ globulins and orosomucoid and was related to the presence of arthritis, it did not correlate with the PIIINP derived antigens or with laminin P1. Thus serum GGT obviously reflects some other aspect of the disease activity than the other variables measured.

The clinical courses of progressive systemic sclerosis-acute, subacute, and chronicaffected the serum concentrations of both PIIINP-Fab antigens and the laminin Pl antigen, though there was a considerable overlap between the groups. This finding suggests that such assays might have prognostic value, but further studies are clearly needed for establishing their possible usefulness. The laminin assay in its present form, with interassay variations of about 15 to $20 \%$, is hardly suitable for follow up of small changes.
Accumulation of connective tissue results from a disturbed balance between its synthesis and degradation. Although it is often assumed that the PIIINP, 7S, and laminin Pl antigens in blood are related to the synthesis of the respective extracellular matrix proteins, they may in some situations as well be derived from the breakdown of the corresponding proteins in tissues. ${ }^{13}$ This might explain the fact that we could only show a weak correlation of the serum concentrations of PIIINP with the clinical subsets of progressive systemic sclerosis. Our findings for PIIINP are remarkably similar to those in rheumatoid arthritis, ${ }^{28}$ a disease that does not lead to development of extensive fibrosis. It can be postulated that in rheumatoid arthritis the degradation of connective tissue keeps pace with its synthesis rate, leading to no net accumulation, whereas in progressive systemic sclerosis the mechanisms responsible for adequate catabolism of collagen, in relation to its synthesis, could be defective. To test this hypothesis we should need separate assays that would unequivocally reflect either the rate of synthesis or the rate of degradation of a certain collagen type.

This study was supported in part by grants from the Academy of Finland and from Hoechst Fennica Ltd. The authors gratefully acknowledge the expert technical assistance of Ms Sirkka Vilmi and Ms Aila Utoslahti.

1 Winkelmann R K. Pathogenesis and staging of scleroderma. Acta Derm Venereol (Stockh) 1976; 56: 83-92.

2 Fleischmajer R. The pathophysiology of scleroderma. Int $\mathcal{f}$ Dermatol 1977; 16: 310-8.

3 LeRoy E C. The connective tissue in slceroderma. Collagen and Related Research 1981; 1: 301-8.

4 Bauer E A, Santa Cruz D J, Uitto J, Eisen A Z. Disorders associated with collagen biosynthesis. Dermatological diseases as prototypes for collagen abnormalities. In: Uitto J, Perejda A J, eds. Connective tissue disease. Molecular pathology of the extracellular matrix. New York: Marcel Dekker, 1987: 249-61.

5 Jimenez S A, Feldman G, Bashey R I, Bienkowski R, Rosenbloom J. Co-ordinate increase in the expression of type I and type III collagen genes in progressive systemic sclerosis. Biochem $\mathcal{f}$ 1986; 237: 837-43.

6 Kähäri V-M, Vuorio T, Näntö-Salonen K, Vuorio $\mathrm{E}$ Increased type I collagen mRNA levels in cultured Increased type I collagen mRNA levels in cultured
scleroderma fibroblasts. Biochim Biophys Acta 1984; 781: scleroder.

7 Peltonen L, Palotie A, Myllylä R, Krieg T, Oikarinen A. Collagen biosynthesis in systemic scleroderma: regulation of posttranslational modifications and synthesis of procollagen in cultured fibroblasts. F Invest Dermatol 1985; 84: $14-18$.

8 Fleischmajer R, Gay S, Meigel W N, Perlish J S. Collagen in the cellular and fibrotic stages of scleroderma. Arthritis Rheum 1978; 21: 418-28.

9 Black C M, Duance V C, Sims T J, Light N D. An investigation of the biochemical and histological changes in the collagen of the kidney and skeletal muscle in systemic sclerosis. Collagen and Related Research 1983; 3: 231-44.

10 Risteli L, Risteli J. Radioimmunoassays for monitoring connective tissue metabolism. Rheumatology 1986; 10: $216-45$.

11 Risteli L, Risteli J. Analysis of extracellular matrix proteins in biological fluids. Methods Enzymol 1987; 145: 391-411.

12 Kivirikko K I, Savolainen E-R. Hepatic collagen metabolism and its modification by drugs. In: Testa B, Perrissound D, eds. Liver drugs: from experimental pharmacology to therapeutic application. Boca Raton: CRC Press, 1988: 193-222.

13 Risteli $L$, Risteli J. Noninvasive methods for detection of organ fibrosis. In: Rojkind M, ed. Connective tissue in health

and disease. Vol I. Boca Raton: CRC Press, 1990: 61-98. Krieg T, Langer I, Gerstmeier H, et al. Type III collagen aminopropeptide levels in serum of patients with progres-
sive systemic scleroderma. $\mathcal{F}$ Invest Dermatol 1986; 87: s88-91.

15 Masi A T, Rodnan G P, Medsger T A Jr, et al. Preliminary criteria for the classification of systemic sclerosis (scleroderma). Arthritis Rheum 1980; 23: 581-90.

16 Anttinen $H$. Collagen glucosyltransferase activity in human serum. Clin Chim Acta 1977; 77: 323-30.

17 Myllylä R. A time-dependent increase in galactosylhydroxylysylglucosyltransferase activity in human blood. Clin Chim Acta 1985; 147: 35-40.

18 Myllylä R, Risteli L, Kivirikko K I. Collagen glucosyltransferase. Partial purification and characterization of the 
enzyme from whole chick embryos and chick-embryo cartilage.

19 Niemelä O, Risteli L, Sotaniemi E A, Risteli J. Type IV collagen and laminin-related antigens in human serum in alcoholic liver disease. Eur $\mathcal{F}$ Clin Invest 1985; 15: 132-7.

20 Rohde H, Vargas L, Hahn E, Kalbfleisch H, Bruguera M, Timpl R. Radioimmunoassay for type III procollagen peptide and its application to human liver disease. Eur $\mathcal{J}$ Clin Invest 1979; 9: 451-9.

21 Rohde H, Bruckner P, Timpl R. Immunochemical properties of the aminopropeptide of procollagen type III. Eur $\mathcal{f}$ Biochem 1983; 135: 197-202.

22 Rohde H, Langer I, Krieg T, Timpl R. Serum and urine analysis of the aminoterminal procollagen peptide type III by radioimmunoassay with antibody Fab fragments. Colby radioimmunoassay with antibody Fab

23 Wallenstein S, Zucker C L, Fleiss J L. Some statistical methods useful in circulation research. Circ Res 1980; 47: $1-9$.

24 Glantz S A. Primer of biostatistics. New York: McGraw-Hill, 1981

25 Majewski A, Skiendzielewska A, Makiela B, Jablonska S, Blaszczyk M. Serum levels of type III collagen aminopropeptide in patients with systemic scleroderma. Arch Dermatol Res 1987; 279: 484-6.
26 Hørslev-Petersen K, Ammitzbøll T, Engström-Laurent A, et al. Serum and urinary aminoterminal type III procollagen peptide in progressive systemic sclerosis: relationship to sclerodermal involvement, serum hyaluronan and urinary collagen metabolites. F Rheumatol 1988; 15: 460-7.

27 Zachariae $H$, Halkier-Sørensen L, Heickendorff L. Serum aminoterminal propeptide of type III procollagen in progressive systemic sclerosis and localized scleroderma. Acta Derm Venereol (Stockh) 1989; 69: 66-70.

28 Hørslev-Petersen K, Bentsen K D, Engström-Laurent A, Junker $\mathbf{P}$, Halberg $\mathbf{P}$, Lorenzen I. Serum amino terminal type III procollagen peptide and serum hyaluronan in rheumatoid arthritis: relation to clinical and serological parameters of inflammation during 8 and 24 months' parameters of inflammation during 8 and 24 months treatment with levamisole, penicil

29 Bentsen K D, Henriksen J H, Bendtsen F, Hørslev-Petersen $\mathrm{K}$, Lorenzen I. Splanchnic and renal extraction of circulating type III procollagen aminoterminal propeptide in patients with normal liver function and in patients with alcoholic cirrhosis. Hepatology 1990; 11: 957-63.

30 Gerstmeier H, Gabrielli A, Meurer M, Brocks D, BraunFalco $\mathrm{O}$, Krieg $\mathrm{T}$. Levels of type IV collagen and laminin fragments in serum from patients with progre sclerosis. F Rheumatol 1988; 15: 969-72. 